\title{
Ursula Bähler, Gaston Paris et la philologie romane
}

\section{Stefania Vignali}

\section{OpenEdition}

\section{Journals}

\section{Edizione digitale}

URL: http://journals.openedition.org/studifrancesi/27146

DOI: 10.4000/studifrancesi.27146

ISSN: 2421-5856

\section{Editore}

Rosenberg \& Sellier

\section{Edizione cartacea}

Data di pubblicazione: 31 décembre 2006

Paginazione: $571-572$

ISSN: 0039-2944

Notizia bibliografica digitale

Stefania Vignali, « Ursula Bähler, Gaston Paris et la philologie romane », Studi Francesi [Online], 150 (L

III) | 2006, online dal 30 novembre 2015, consultato il 08 novembre 2020. URL : http://

journals.openedition.org/studifrancesi/27146; DOI : https://doi.org/10.4000/studifrancesi.27146

Questo documento è stato generato automaticamente il 8 novembre 2020.

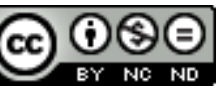

Studi Francesi è distribuita con Licenza Creative Commons Attribuzione - Non commerciale - Non opere derivate 4.0 Internazionale. 


\title{
Ursula Bähler, Gaston Paris et la philologie romane
}

\author{
Stefania Vignali
}

\section{NOTIZIA}

URSULA BÄHLER, Gaston Paris et la philologie romane, Genève, Droz, 2004, pp. 873.

1 L'intento di questa ricerca è fornire un contributo alla storiografia della filologia romanza attraverso l'analisi del «caso» Gaston Paris, condotta prevalentemente a partire dalla corrispondenza del grande filologo già in parte pubblicata dall'autrice stessa.

2 Una prima sezione di quest'analisi è consacrata allo studio della biografia di G.P., la cui vita privata e scientifica appaiono strettamente correlate tra loro, in maniera a volte problematica. L'esposizione, che segue un ordine cronologico, è intercalata da ampi stralci della corrispondenza privata di G.P. L'autrice illustra poi le caratteristiche globali dell'opera di colui che fu il centro di gravitazione del movimento filologico della seconda metà del XIX secolo, partendo dalla natura dei suoi contributi; questi vengono suddivisi per tipologia, sottolineando talvolta qualche elemento utile a fornire un profilo psicologico dello studioso.

3 La seconda parte di questo lavoro è incentrata sulla passione per gli studi filologici che animò G.P. e che investì tutto il suo universo intellettuale. Qui l'A. fornisce un quadro generale del personaggio, indispensabile per comprendere il contributo che lo studioso fornì alla filologia. L'analisi verte su due punti centrali: l'autoriflessività del discorso filologico dello studioso ed un'analisi dei motivi che lo guidarono nelle sue scelte teoriche. Lo scopo di questa sezione è quello di determinare l'identità della filologia romanza in Francia, sulla base di diverse tipologie di testo e di diverse visioni della disciplina elaborate durante il XIX secolo; inoltre, vengono evidenziati alcuni meccanismi che stanno alla base della definizione stessa di filologia romanza che G.P. ed i suoi colleghi elaborarono, contribuendo in modo determinante a farne una 
disciplina scientifica. Partendo da un ambito più generale, che analizza il rapporto con la scienza, la studiosa analizza il contributo del filologo alle diverse discipline storiche, per convergere infine verso un discorso circoscritto alla sola filologia romanza, punto centrale di questa seconda sezione.

4 La terza parte ruota attorno all'"amore per la dolce Francia", concetto chiave per lo sviluppo della disciplina oltr'Alpe negli anni intorno al 1860, mostrando l'implicazione dell'idea di nazione e di nazionalità. L'interesse è principalmente quello di esaminare in che modo il discorso filologico di G.P. si possa inserire in un ambito di tipo nazionalistico e quali siano i valori semantici veicolati dalle nozioni di nazione, patriottismo e genio nazionale. Persistendo su una linea biografica, l'analisi si propone di evidenziare i rapporti tra filologia romanza e "complesso nazionale", che si fonda su due piani diversi: quello della disciplina in sé e quello degli oggetti di studio della disciplina.

5 La quarta ed ultima sezione è consacrata all'immagine che G.P. si fece della letteratura medievale. Fondandosi su numerosi esempi e separando la materia di Francia dalla materia bretone, U.B. traccia le linee di forza che sembrano maggiormente caratterizzare le argomentazioni e l'immaginario di G.P., insistendo sull'importanza della scientificità in generale e della metodologia in particolare.

6 A queste quattro sezioni segue una breve conclusione, dove l'autrice sottolinea l'importanza della riflessione del maestro non solo sulla propria disciplina o sul suo fare scientifico, ma soprattutto sul ruolo che la scienza in generale è chiamata a svolgere nella direzione morale dell'uomo moderno: egli ha realizzato un progetto di vita, non fermandosi alla semplice teoria. Infine l'autrice propone numerose appendici disposte in ordine cronologico dove figurano alcune missive, alcuni poemi e un curriculum vitae del filologo estremamente dettagliato.

7 A queste conclusioni segue una ricca sezione bibliografica divisa in due sezioni: una prima parte che ripropone la bibliografia delle opere di G.P. redatta da Mario Roques e da Joseph Bédier nel 1904, fino ad oggi di difficile accesso, ed accompagnata da un breve errata corrige, mentre la seconda parte è dedicata alle opere citate nel testo. Il lavoro si chiude con un indice dei nomi propri e delle opere anonime. 